\title{
COSTISTRICKLANDIA LIRATA (PENTAMERIDA, BRACH.) ИЗ ВЕРХНЕГО ЛЛАНДОВЕРИ ЭСТОНИИ
}

Costistricklandia lirata (Sowerby) - одна из руководящих форм в раковинной фауне позднего лландовери Северной Европы. Этот вид характерен для верхней части верхнего лландовери Англии, Уэльса, Норвегии, о-ва Готланд, но встречается также и в низах венлока (St. Joseph, 1935, 1938; Ziegler и др., 1968; Cocks, 1971; Bassett, Rickards, 1971; Walmsley, Bassett, 1976; Bassett, 1977).

До последнего времени находок Costistricklandia из силура Әстонии не было, хотя ее предок - род Stricklandia - здесь широко распространен (Рубель, 1970, 1977). Летом 1976 г. авторами данной статьи были обнаружены на юго-западной окраине пос. Вяндра на правом берегу реки того же названия в двух слоях толщиной около 5 cм частично выщелоченные раковины Costistricklandia (см. описание). Здесь же на дне реки, у самого уреза воды, выходил слой с многочисленными Pentameroides, который в верхнем лландовери Уэльса весьма часто встречается вместе с родом Costistricklandia (см. Ziegler и др., 1968). Кроме того, было установлено еще несколько мест обитания Pentameroides в окрестностях Вяндра (рис. 1). Для определения местоположения слоев c Costistricklandia и Pentameroides в сводном разрезе адавереского горизонта были отобраны пробы на хитиновые микроорганизмы, обработанные В. Нестор.

Согласно современным представлениям (Эйнасто и др., 1972; Нестор, 1972; Аалоэ и др., 1976), адавереский горизонт в Западной Эстонии состоит из согласно залегающих друг на друге румбаской и велизеской свит. Румбаская свита (= пентамеровые слои по Эйнасто и др., 1972; Нестор, 1972) сложена илисто-детритовыми известняками различной степени глинистости со скоплениями вида Pentamerus

Рис. 1. Схема местонахождений Costistricklandia lirata (черный треугольник) и Pentameroides (пустой треугольник) в Эстонии.

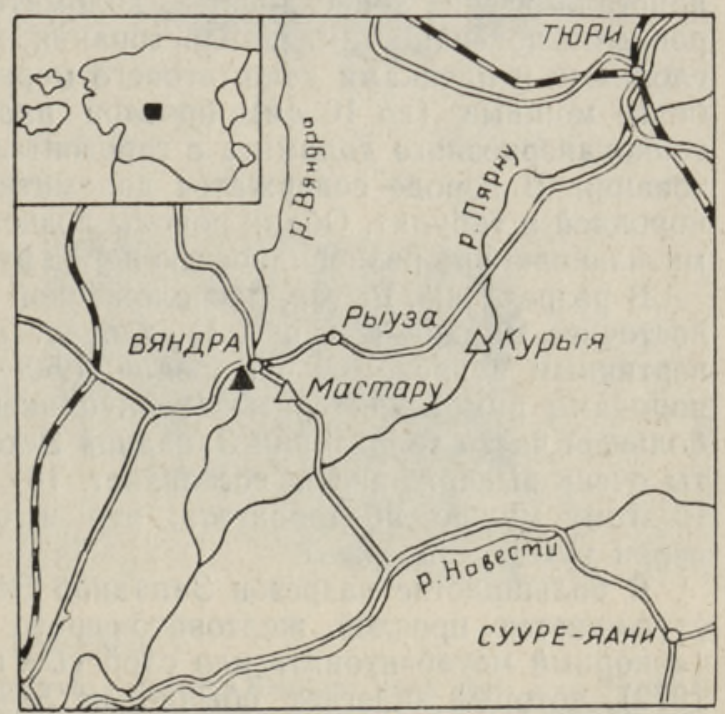




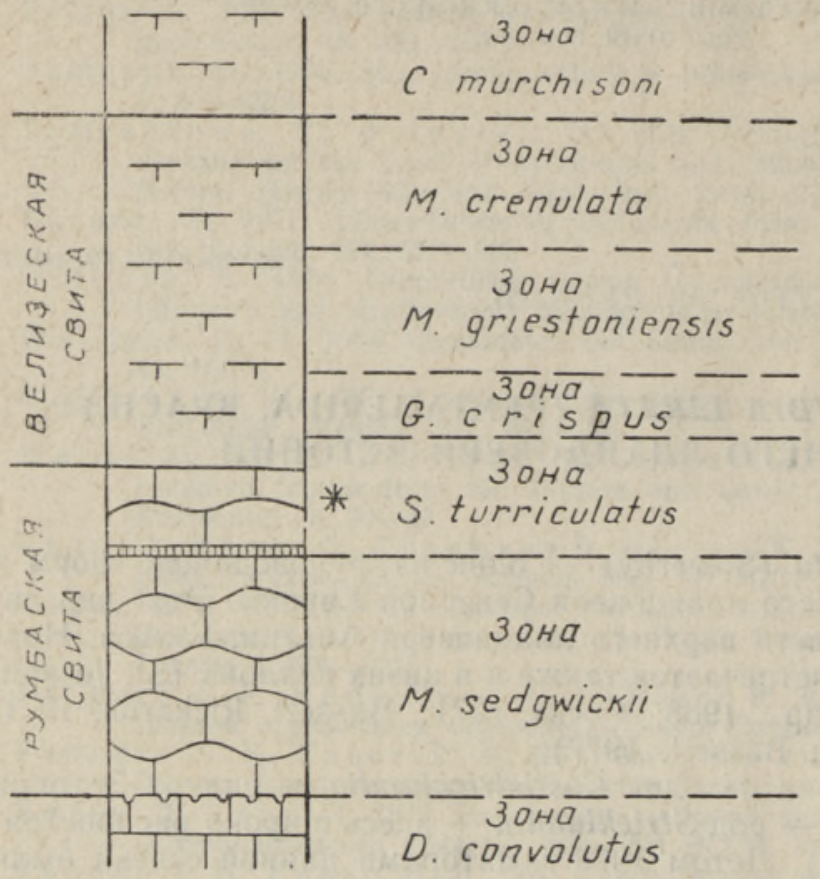

$1-1$
3

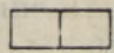

4 파
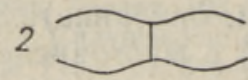

Рис. 2. Приблизительное сопоставление сводного разреза адавереского горизонта в Западной Эстонии с граптолитовой шкалой. Звездочкой отмечен уровень с Costistricklandia lirata. 1 - мергель, 2 - комковатый глинистый известняк, 3 - скрытокристаллический и детритовый известняки, 4 опорный слой метабентонита.

oblongus (Sowerby), велизеская свита - мергелями и аргиллитами с брахиоподами сообщества Clorinda (рис. 2). Граница между ними считается более или менее синхронной (Эйнасто и др., 1972) и проходяшей где-то на уровне граптолитовой зоны Spirograptus turriculatus s. 1. (Hестор, 1972).

Породы, обнажающиеся на р. Вяндра, представляют собой тонкокристаллические тонкослоистые доломиты и глинистые доломиты с неровными поверхностями напластования, перемежающиеся тонкими прослойками и пленками доломитового мергеля. Встречаются единичные и более мощные (до 10 cм) прослои плотного среднекристаллического тонкокавернозного доломита с горизонтальными поверхностями напластования. В породе содержатся доломитизированные остатки строматопороидей и табулят. Облик породы позволяет считать ее вторично доломитизированной разновидностью пород румбаской свиты.

В разрезе скв. Рыуза, расположенной приблизительно в $5 \kappa м$ северовосточнее Вяндра (см. рис. 1), адавереский горизонт залегает под четвертичным покровом в интервале 1,50-15,60 $м$ и сложен полностью породами румбаской свиты (неопубликованные данные Э. Кала). На большей части территории Западной Эстонии мощность румбаской свиты очень выдержанна и составляет 18-20 м (Эйнасто и др., 1972). Поэтому можно предполагать, что в окрестностях Вяндра выходят верхи румбаской свиты.

В большинстве разрезов Западной Эстонии в румбаской свите прослеживается прослой желтовато-серого алевритистого метабентонита («опорный метабентонит» или слой « $O$ » по обозначению Эйнасто и др., 1972), который залегает обычно на 5-6 м ниже кровли румбаской 

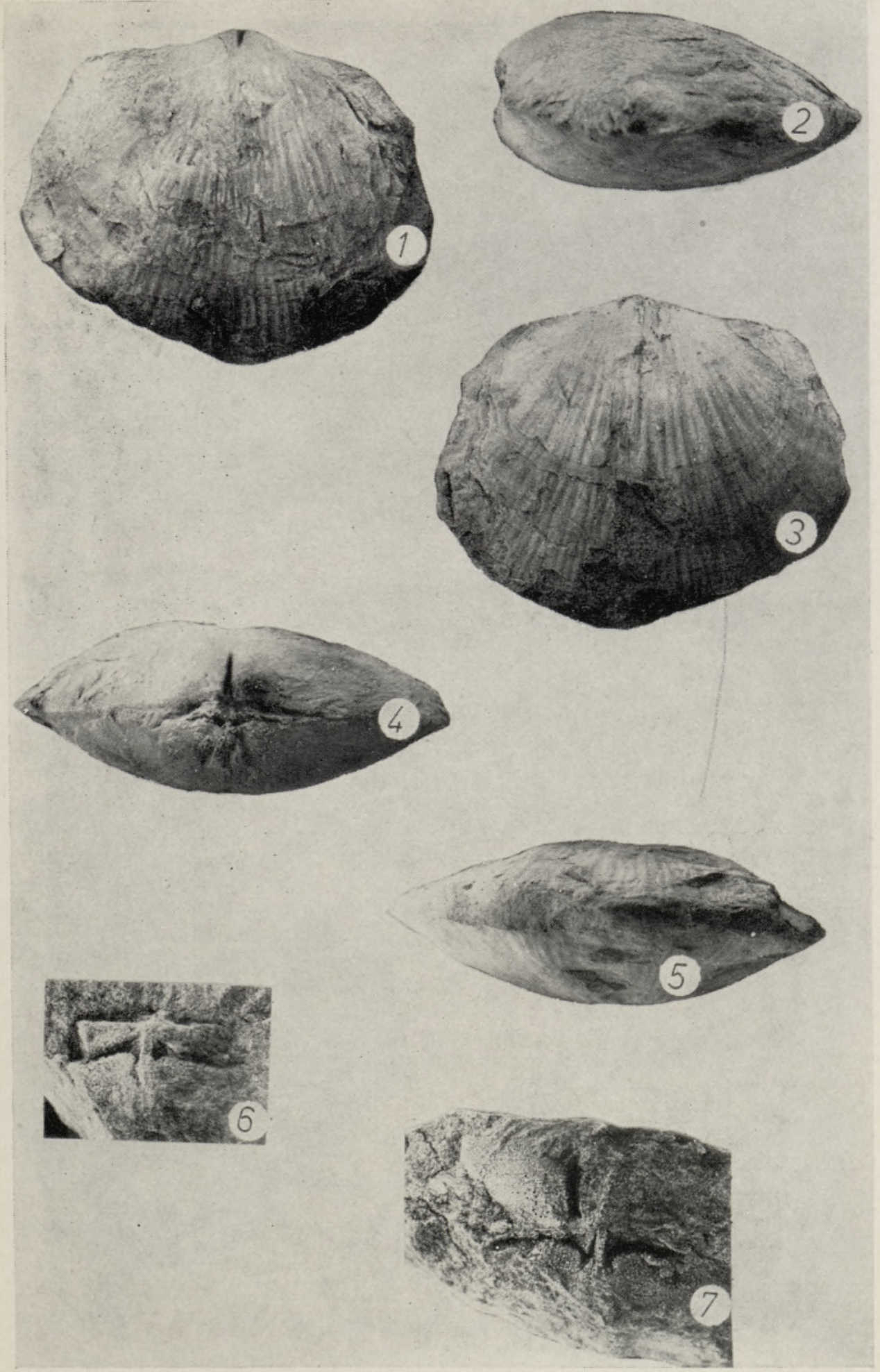

ТАБЛИЦА I

Costistricklandia lirata (Sow.), адавереский горизонт, Вяндра. Увел. фиг. $1-5-\times 1$, фиг. 6 и $7-\times 2$. Фиг. $1-5-$ частично выщелоченная раковина $\mathrm{Br} 3788$, вид со стороны брюшной (1) и спинной (3) створок, сбоку (2), сзади (4) и спереди (5). Фиг. 6 ядро замка спинной створки, $\mathrm{Br}$ 3793. Фиг. 7 - ядра примакушечной части брюшной и спинной створок, $\mathrm{Br} 3792$. 

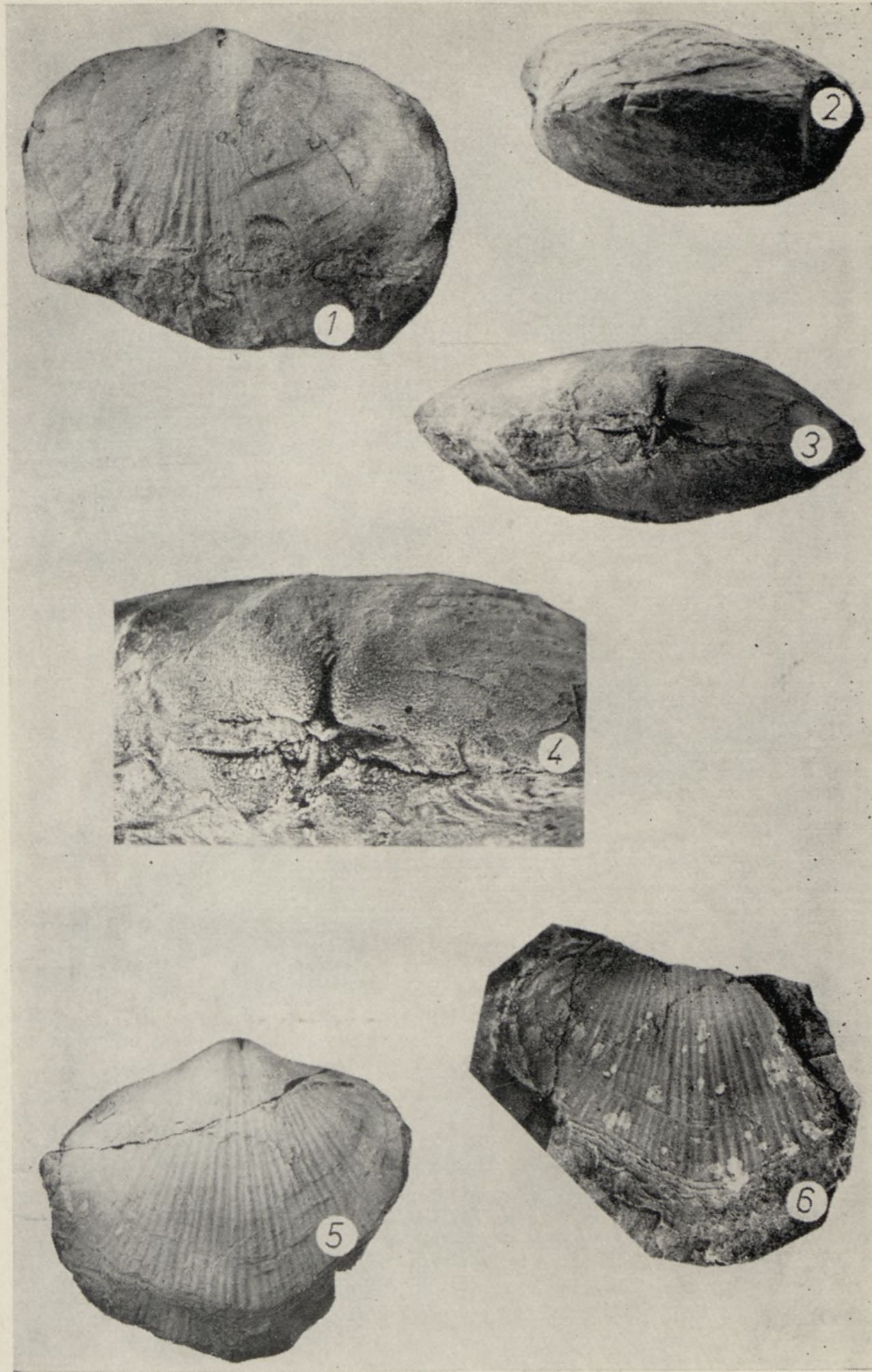

ТАБЛИЦА II

Costistricklandia lirata (Sow.), адавереский горизонт, Вяндра. Увел. фиг. $1-3,5,6-$ $\times 1$, фиг, $4-\times 2$. Фиг. $1-3-$ частично выщелоченная раковина $\mathrm{Br} 3789$, вид со стороны брюшной створки (1), сбоку (2) и сзади (3). Фиг. 4 - она же, вид на примакушечную часть сзади. Фиг, 5 - ядро брюшной створки, $\mathrm{Br} 3790$, Фиг, 6 - ядро внешней скульптуры брюшной створки, $\mathrm{Br} 3791$. 
свиты. В неглубокой скважине, пробуренной в пос. Вяндра недалеко от обнажения с Costistricklandia, на уровне 5,75-6,05 $\mu$ проходит сходный слой метабентонита (неопубликованные данные Х. Пальмре). Учитывая рельеф местности, можно с уверенностью сказать, что слои с Costistricklandia действительно залегают в верхах румбаской свиты на $3-5 \mathrm{M}$ выше этого слоя метабентонита.

Для определения возраста слоев с Costistricklandia и Pentameroides был изучен также состав четырех проб с р. Вяндра на присутствие хитинозой. Установлено наличие Conochitina sp. n., Eisenackitina dolioliformis Umnova, Angochitina sp. п. и Ancyrochitina ancyrea (Eisenack). Два первых вида характерны для всего адавереского горизонта Западной Эстонии, за исключением низов румбаской свнты. Последний вид распространен по всему силуру. Angochitina sp. n., вероятный предок вида Angochitina longicollis Eisenack (главное отличие - отсутствие специфичной четкой орнаментации на поверхности камеры), встречается обильно во всех исследованных пробах. Единичные Angochitina sp. n. обнаружены еще в разрезах скв. Кирикукюла и Икла в верхах румбаской свиты, а в разрезе скв. Охесааре - в самых низах (проба с глубины 372,1 м) велизеской свиты, соответствующих, согласно Д. Кальо (Кальо, ред., 1970), граптолитовой зоне Spirograptus turriculatus. Выше по разрезу появляется Angochitina longicollis, который в пробах с p. Вяндра не был обнаружен. В этих же пробах отсутствовали и другие, характерные для верхней части велизеской свиты виды Conochitina proboscifera Eisenack, C. cf. visbyensis Laufeld, Desmochitina densa Eisenack.

Итак, приведенные данные позволяют заключить, что находки Costistricklandia в Әстонии приурочены к верхам румбаской свиты, и по граптолитовой шкале они не моложе зоны Spirograptus turriculatus (cм. также Нестор, 1972).

Найденные экземпляры явно относятся к подвиду Costistricklandia lirata lirata (см. описание), появление которого, по мнению Л. Р. Кокса (Cocks, 1971), совпадает с граптолитовой зоной crenulata. Ннже, в отложениях, соответствующих зонам crispus и griestoniensis (по тем же данным), широкое распространение получает подвид C. lirata alpha, а зона turriculatus - это уже время развития предкового рода Stricklandia. В связи с расхождением стратиграфической датировки эстонских находок Costistricklandia lirata lirata с ранее установленной, уместно обратить внимание на то, что и некоторые другие представители эволюционного ряда стрикландидных брахиопод (в частности S. lens progressa) в эстонском разрезе появляются необычно «рано» (см. Рубель, 1977). Возможно, что эволюция стрикландидных брахнопод в различных регионах происходила асинхронно.

Семейство Stricklandiidae Schuchert et Cooper, 1931

Род Costistricklandia Amsden, 1953

Costistricklandia lirata lirata (Sowerby, 1839)

Табл. I, фиг. 1-7; табл. II, фиг. 1-6

1977. Costistricklandia lirata lirata - Bassett

табл. 44 , фиг. $1-8$, табл. 45 , фиг. $1-12$, табл. 46 , фиг. $1-6$.

О пи сание. Раковина крупных размеров, овального очертания, умеренно равно-двояковыпуклая, со слегка выдающейся брюшной макушкой. Замочная линия прямая, ее длина составляет около $3 / 5$ наи- 
большей ширины раковины. Низкие вогнутые ареи развиты на обеих створках. В примакушечной части брюшной створки развит слабый синус, а в передней половине спинной створки - неотчетливое возвышение. Внешняя поверхность раковины покрыта низкими и округлыми ребрами, число которых увеличивается за счет вклинивания и раздваивания.

Спондилий маленький, поддерживающая его септа короткая, умбональная полость без утолщений. Кардиналий состоит из внутренних пластин и брахиальных отростков. Первые имеют треугольную форму и расположены относительно друг друга под тупым углом, брахиальные отростки прилегают к ним латерально. Аддукторное поле спинной створки развито неотчетливо.

Р а $з$ м е ры, мм

$\begin{array}{cccc} & \begin{array}{c}\text { Длина брюшной/ } \\ \text { спинной створок }\end{array} & \begin{array}{c}\text { Наиболь- } \\ \text { шая ширина }\end{array} & \text { Толщина } \\ \operatorname{Br} 3788 & 52 / 51 & 64 & 24 \\ \operatorname{Br} 3789 & -/- & 67 & 26 \\ \operatorname{Br} 3790 & 52 /- & 60 & -\end{array}$

3 амечания и сравнение. Наиболее полные описания вида C. lirata даны Дж. Сэнт-Жозефом (St. Joseph, 1935, 1938). Он выделяет среди английского материала три формы - $\alpha, \beta$ и typica - и две первые из них рассматривает как переходные к виду Stricklandia lens, с представителями которого эти формы встречаются вместе. Нет сомнения, что описанные выше экземпляры относятся к форме typica.

В этих же работах Дж. Сэнт-Жозеф указывает и на различия между экземплярами формы typica из лландовери Англии и Норвегии: первые имеют умбональные утолщения, вторые - нет (см. St. Joseph, 1938, c. 333). По имеющимся изображениям и описаниям, эстонские экземпляры более сходны с норвежскими и готландскими, чем с английскими.

В ходе изучения эволюции стрикландидных брахиопод две описанные Дж. Сэнт-Жозефом формы C. lirata возведены в ранг подвида под названиями lirata alpha и lirata lirata (Ziegler и др., 1968; Cocks, 1971). Объем подвида $C$. lirata lirata принят здесь согласно полной синонимике его, приведенной М. Бассетом (Bassett, 1977).

Р аспростр анение. Верхи лландовери $\left(\mathrm{C}_{6}\right)$ и низы венлока Великобритании, верхи лландовери Норвегии $(7 \mathrm{c} \beta)$ и Швеции (Lower Visby Group, см. Bassett, 1977), венлок Новой Земли (Никифорова, 1960) и верхи лландовери (румбаская свита адавереского горизонта, $\mathrm{H}^{\prime} \mathrm{R}$ ) Эстонии.

\section{ЛИ ТЕРА Т У Р А}

А алоэ А., Кальо Д., Кла ам анн Э., Н естор Х., Эйн асто Р. 1976. Стратиграфическая схема силура Эстонии. Изв. АН ЭССР, Хим. Геол., 25, 38-45.

К а льо Д. (ред.). 1970. Силур Эстонни. Таллин, с. 343.

Н е с т о Р Х. 1972. О возрастном диапазоне слоев с Pentamerus oblongus и о характере позднелландоверийской трансгрессии в Северной Европе. Йв. АН ЭССР, Хим. Геол., 21, 344-350.

Н и ки фор ов а О. И. 1960. Отряд Pentamerida. В кн.: Сарычева (ред.). Основы палеонтологин. Мшанки, брахиоподы. М., с. 197-205.

Р у бель М. 1970. Брахиоподы Pentamerida и Spiriferida силура Эстонин. Таллин, с. 75.

Р убель М. 1977. Эволюция рода Stricklandia (Pentamerida, Brach.) в лландовери Эстонии. В сб.: Кальо Д. (ред.). Фации и фауна силура Прибалтики. Таллин, c. $193-212$. 
Э й н а с т о Р., Н ест ор Х., К а л а Э., К а я к К. 1972. Сопоставление верхнелландоверийских разрезов в Западной Эстонии. Изв. АН ЭССР, Хим. Геол., 21, $333-343$.

B a ssett, M. G. 1977. The articulate brachiopods from the Wenlock Series of the Welsh Borderland and South Wales. Palaeontogr. Soc. Monogr., 130, P. 4, $123-176$.

B a ssett, M. G., Cocks, L. R. M. 1974. A review of Silurian brachiopods from Gotland. Fossils and Strata, No. 3, 56 p.

B a ssett, M. G., Rickards, R. B. 1971. Notes on Silurian stratigraphy and correlation in the Oslo district. Norsk geol. Tidsskr., 51, No. 3, 247-260.

Cocks, L. R. M. 1971. Facies relationships in the European Lower Silurian. Mém. Bureau rech. géol. et minières, No. 73, 223-227.

St. J o s e ph, J. K. S. 1935. A critical examination of Stricklandia (= Stricklandinia) lirata (J. de Sowerby) 1839 forma typica. Geol. Mag., 72, No. 9, 401-424.

St. Joseph, J. K. S. 1938. The Pentameracea of the Oslo region. Norsk geol. Tidsskr., 17, 225-336.

Ziegler, A. M., Cocks, L. R. M., McKerrow, W. S. 1968. The Llandovery transgression of the Welsh Borderland. Palaeontology, 11, P. 5, 736-782.

W a $1 \mathrm{msley}$, V. G., B a s sett, M. G. 1976. Biostratigraphy and correlation of the Coralliferous Group and Gray Sandstone Group (Silurian) of Pembrokeshire, Wales. Proc. Geol. Assoc., 87, P. 2, 191-220.

Институт геологии

Академии наук Эстонской ССР

Поступила в редакцию 14/I 1977

Viiu NESTOR, H. NESTOR, M. RUBEL

\section{COSTISTRICKLANDIA LIRATA (PENTAMERIDA, BRACH.) EESTI OLEMLÄNDOUVERIS}

Artiklis on esmakordselt kirjeldatud Eesti ülemländouveri kihtides esinevat alamliiki Costistricklandia lirata lirata (Sow.) ning hinnatud tema stratigraafilist asendit adavere lademe koondtulba (Lääne-Eestis) ja graptoliiditsoonide suhtes (joon. 2).

Viiu NESTOR, H. NESTOR, M. RUBEL

\section{COSTISTRICKLANDIA LIRATA (PENTAMERIDA, BRACH.) IN THE UPPER LLANDOVERY OF ESTONIA}

Costistricklandia lirata lirata (Sow.) is described on the material from the Upper Llandovery of Estonia, and its stratigraphic position there is supposed: the very top of the Rumba Formation of the Adavere Stage and not younger than the turriculatus zone (Fig. 2). 